\title{
A Access of SST Converter Topologies: Control \& Modulation Techniques
}

\author{
Jyoti M. Kharade, P. M. Joshi
}

\begin{abstract}
The Solid State Transformer (SST) is the emerging power electronics based key component of distribution system. In this paper a comparison of SST converter topologies with control and modulation techniques is presented. The main focus is on the use of SST for various applications based on the features offered by different converter topologies with different control techniques. The review is carried out by comparing these power electronics topologies based on their structure, advantages, limitations and their control techniques suitable for different applications such as green energy source integration to grid, traction, controlling of electrical machines, use as a Distributed Generators, due to powerful and attractive features of SST. The three stage SST is considered and compared for converter topologies with their control and modulation schemes which will help to identify the suitability of SST for the application.
\end{abstract}

Index Terms - Solid State Transformer (SST), Conventional Transformer, Cascaded H-Bridge Converter (CHB), Dual Active Bridge Converter (DAB), Multilevel Converter, Smart Grid.

\section{INTRODUCTION}

Before twentieth century, the development of distribution transformer by L. Gaulard and J. D. Gibbs got much prominence in ac power transmission and distribution systems. Liu G, Polis MP, and Wang B. have worked on this concept of Solid State Transformer and received patent in 1999. Consequently series of researches has been carried out with multifunctional, multilevel, power electronics transformer with different control strategies, switching and modulation techniques in 1999 [16] consequently in 2005, 2006 and 2011.

The conventional transformer preferably used to perform operations as voltage transformation as per system requirement and loading conditions and isolation purpose. But the conventional distribution transformers shows saturation in the core and generate harmonics which may results in huge inrush currents and can create power quality issues due to increased nonlinear loads in the distribution system. This leads to addition of power filters which make the supply system complicated and expensive. Moreover, the conventional distribution transformer, being static device, does not play any dynamic role in compensating for voltage sag or swell. It does not have facility to integrate renewable energy sources as PV cells and fuel cells (dc sources).

The more focus is being given to design the smart grids

Revised Version Manuscript Received on 16 September, 2019.

Miss. Jyoti M. Kharade, Research Scholar, Assistant Professor, Department of Electrical Engineering, AnnasahebDange College of Engineering and Technology Ashta, Maharashtra, India.

(Email: jmk_ele@adcet.in)

Dr. P. M. Joshi, Research Guide, HOD, Professor, Department of Electrical Engineering, Government College of Engineering, Karad, Maharashtra, India.

(Email:dr.pmjoshi@gmail.com) with improved power quality [22] [23] (by mitigating voltage sags, reducing failures or interruptions) with increased efficiency. The Solid SST is the key solution for the smart grid with increased renewable energy sources penetration and electric vehicle and traction loads.

Considering these limitations present day researchers are focusing more on advanced power electronics structured transformer, SST, to provide high speed power processing. The SST is basically introduced as high voltage, high frequency transformer along with many other components such as power electronic devices, gate driver circuits, heat sinks, cooling circuits, control circuits and other ancillary devices and systems.

The major scheme of SST is expected to provide various functionalities consist of potential features like power quality improvement at sensitive load, fault isolation, fault current limitation, instantaneous voltage regulation, etc along with availability of various ac and dc voltage levels to integrate DGs.

For the penetration of distributed green energy sources SST is being treated as one of the widely advanced modern research interest [8] [9] [10]. The research study is segregated in to two ways as one is to develop the architecture and modeling of SST and another is to determine the suitability of Solid state Transformer for various applications [13].

In recent years, most of the research is focused on the applications of SST with different power electronics converters build transformer as Solid State Transformer. Several researchers are finding the applicability and suitability of the SST for various applications. Edward R. Ronan et al. [17] have implemented prototype of SST to confirm the desirable features as improved power quality, reduced size of system, power factor improvement, self protection which are unavailable in conventional transformer.

D. K. Rathod has presented the discussion about the extending Solid State Transformer (SST) through analysis of recent expansion in the field of power system [4]. The various SST configurations have presented with various converter topologies such as single stage, two stage and three stage SST for both LVDC and HVDC. They have identified future benefits of SST for integration with other systems and also used to enhance the use in MV and LV applications. The conventional transformer having disadvantages such as bulkiness, core saturation for variable load, low voltage regulation issues can be lowered by SST as an intelligent transformer. SubhadeepPaladhi and Ashok S. have discussed 
the application of SST for green energy as wind energy based distributed generation system [13]. The general traditional way of wind power integration to grid and SST interfaced wind farms have discussed with modeling of advanced SST system includes converter stages. The discussion has carried out by case study of practical data of wind farm with layout of the system. The system have analyzed with SST for active and reactive power control using simulation tools [11] [12]. ArindamMaitra et al. [20] have analyzed potential of SST as development of $100 \mathrm{kVA}, 15 \mathrm{kV}$ prototype of Intelligent Universal Transformer (IUT) with different features as high frequency AC service as well as DC service and discussed impact on a wide range of applications such as electrical vehicles, PV integration, distribution transformer, energy storage interfacing, with reliable and secure communication.

In this paper different multilevel converter topologies for SST have discussed and compared for different applications. Though the proper converter topology selection is important, it is most important to select suitable switching control techniques for acceptable performance of system expecting capacitor voltage balancing, switching of semiconductor devices, bidirectional power flow, efficient and reliable operation. The SST can be used alternative to conventional transformer having wider area of applications. The discussion about various SST converter topologies, their control schemes, comparison on different basis has presented in different sections. The introduction of current scenario in the generations of power electronics converters has discussed in section 1. Followed with this, in section 2, the disadvantages of classical transformer, actual concept of SST and its advantages have explained and compared. The detailed descriptions of different converters with their controlling methods have reviewed in section 3. In section 4 concluding remarks have highlighted.

A. Disadvantages of Classical Distribution Transformer:

The typical distribution transformers have the following disadvantages:

1. Bulky size and heavy weight

\section{Considerable voltage drop under load}

3. Large inrush currents due to harmonics produced by core saturation

4. At average operation load produces relatively high losses.

\section{Power quality issues}

6. Poor voltage regulation at distribution side.

B. Advantages of SST over traditional transformer:

The SST provides superiority over conventional distribution transformer due to following feature:

1. Volume and weight reduction

2. Voltage sag compensation

3. Fault isolation, limiting fault current

4. DC Output

5. Power quality improvement at sensitive loads

6. Outage compensation

7. Instantaneous voltage regulation

8. Power Factor (PF) correction

9. Metering or advanced distribution automation

The above listed features can be accomplished by employing the conception of SST.

\section{SOLID STATE TRANSFORMER STRUCTURE}

The Solid State Transformer (SST) is a power electronics interface which combines converters, medium or high frequency transformers, and controlling circuitry. The primary thought is to replace the $50 \mathrm{~Hz}$ or $60 \mathrm{~Hz}$ traditional transformer with a medium or high frequency transformer that can facilitates an important decrease in weight, size and volume.

The SST is an advanced component or system which consists of multistep converter isolated with high frequency operated transformer. The SST structure is illustrated in fig. 1 consist of $\mathrm{AC} / \mathrm{DC}, \mathrm{DC} / \mathrm{DC}$ and $\mathrm{DC} / \mathrm{AC}$ converters from where integration to $\mathrm{AC}$ grid is possible.

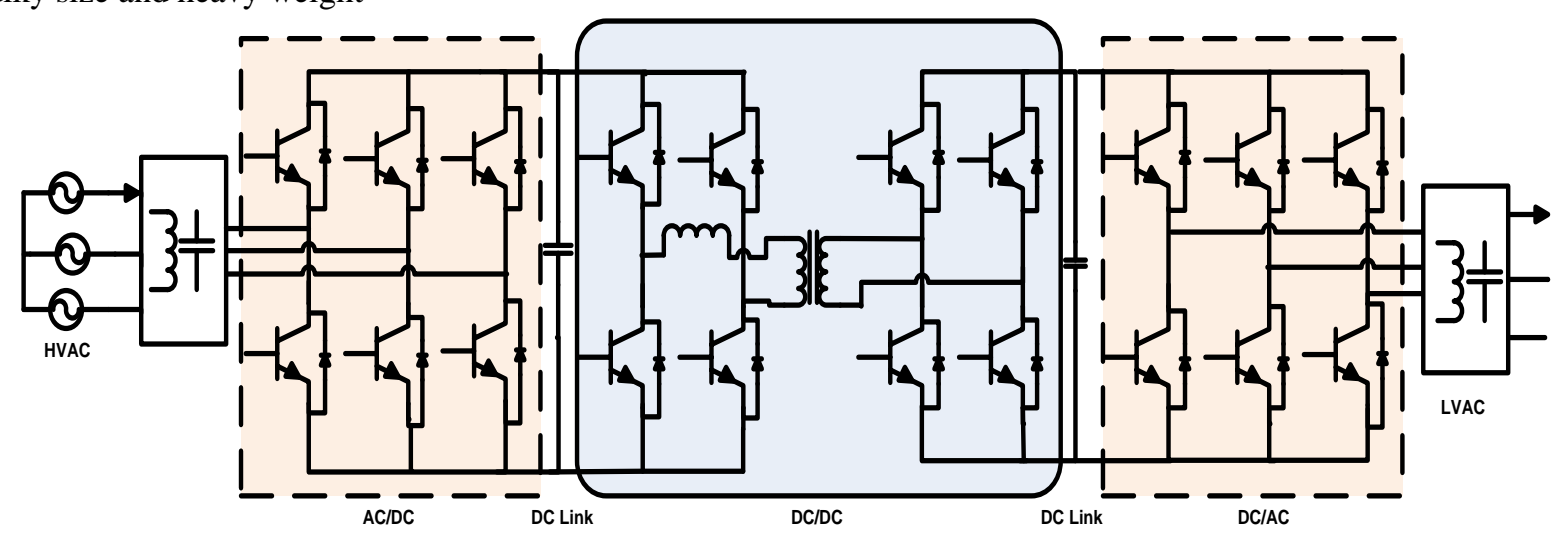

Fig. 1: Solid State Transformer Structure

The SST can be designed with various combinations of converter topologies such as Cascaded $\mathrm{H}$ bridge (CHB) converter, Dual Active Bridge (DAB) converters, Modular Multilevel Converters (MMC) etc as depending on the applications and suitability [15].

\section{SST COVERTER TOPOLOGIES\& RESULTS}

The SST consists of multi-stage such as AC/DC, DC/DC and DC/AC. The SST can be formed by various ways using different combinations of these converters. In this paper Three stage SST is described. For these three different stages different types of converter topologies and their modulation schemes have discussed. 
The first stage of SST consist an AC/DC converter stage may be designed with following converter topologies:

1. Diode Clamped or Neutral Point Clamped Converter (NPCC)

2. Flying Capacitor Converter (FCC)

3. Cascaded H Bridge Converter (CHBC)

4. Hybrid Modular Multilevel Converter (MMC)

The topologies are shown in fig 2(a - d). The Diode Clamped or Neutral Point Clamped Converter (Fig. 2a) has simplest structure due to only one isolated DC source requirement. This topology can regulate the reactive power and uses fundamental frequency for switching operation. But due to more number of diodes system becomes impractical and due to capacitor unbalancing the active power control is difficult. The similar topology is modified with clamped capacitor (Fig.2b) instead of clamped diodes. So that it reduces the THD and enables active power balancing and compensation of reactive power. But because of more number of capacitors the system becomes bulky, complex as well as expensive. The advanced converter is designed by connecting series full or half bridges providing separate DC

source which offers more simple and scalable structure (Fig. 2c). In most of the power electronics systems such as integration of renewable energies to grid [7] [14], Solar and wind hybrid system, Cascaded $\mathrm{H}$ bridge multilevel inverter/ converters are used. The Modular Multilevel Converter is advanced hybrid converter topology (Fig. 2d) which consists of cascaded half $\mathrm{H}$-bridge cells as submodules and two level converter combination. These submodules minimize the THD so that it eliminated the need of filters of large size. It provides the suitability for applications such as motor drives, HVDC etc. [5]

The control strategies for first stage of SST converters can be designed with the different schemes illustrated in fig. 3 .

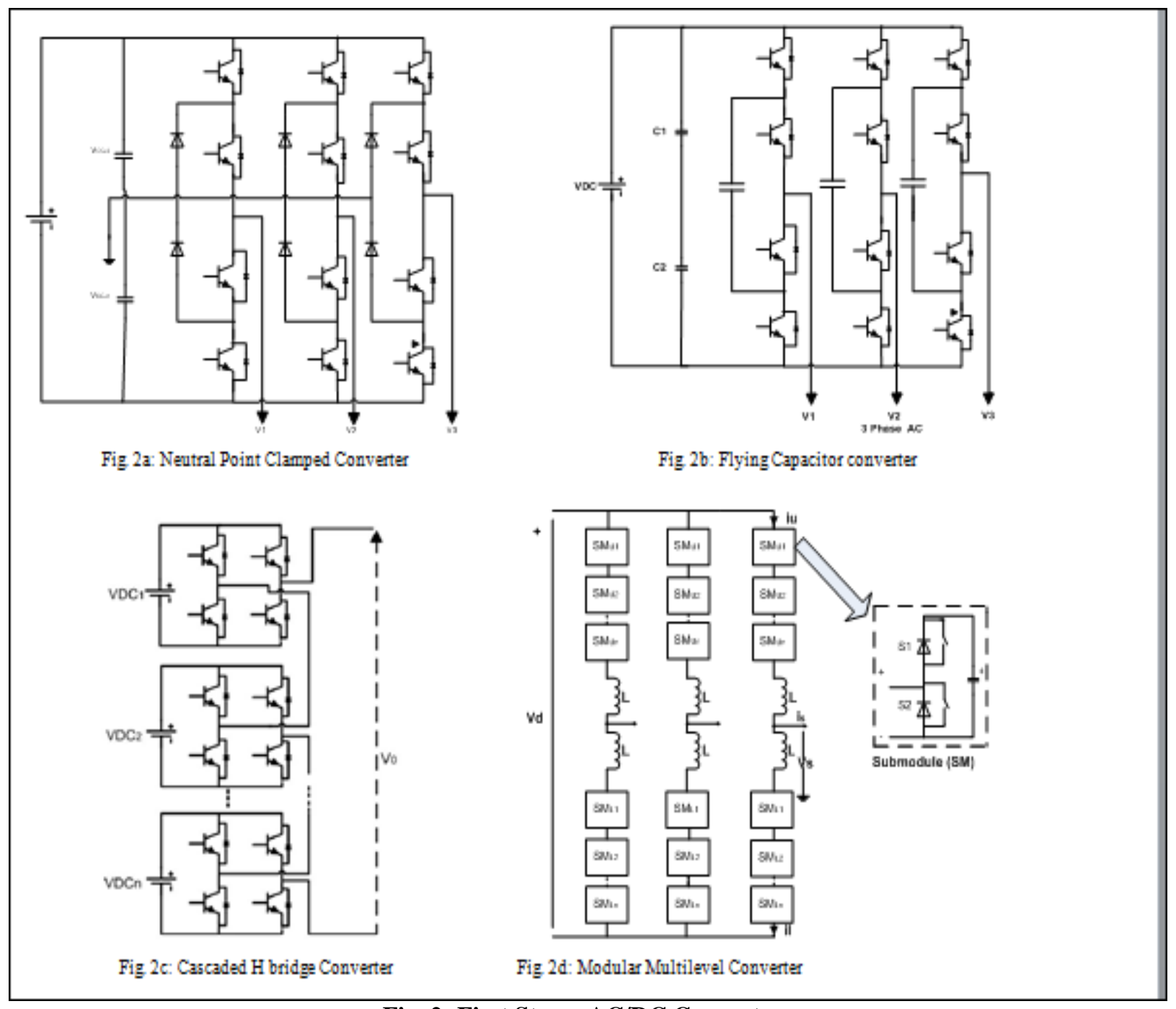

Fig. 2: First Stage: AC/DC Converters

Converter is advanced hybrid converter topology (Fig. 2d) which consists of cascaded half $\mathrm{H}$-bridge cells as submodules and two level converter combination. These submodules minimize the THD so that it eliminated the need of filters of large size. It provides the suitability for applications such as motor drives, HVDC etc. [5]

The control strategies for first stage of SST converters can be designed with the different schemes illustrated in fig. 3 . 


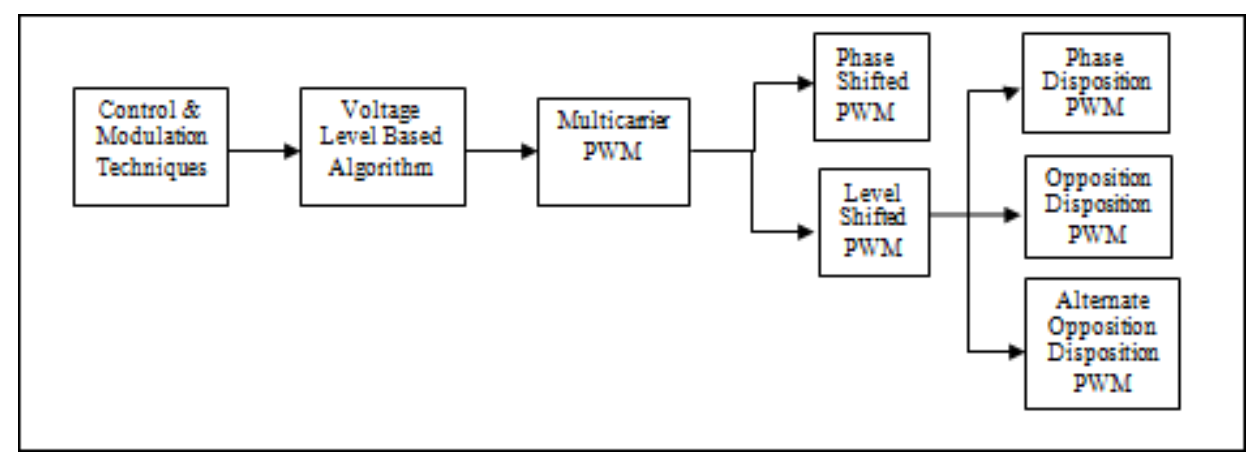

Fig 3: Modulation Techniques for AC/DC Converters

The Phase Shifted PWM is particularly developed to control Cascaded H-Bridge Converter [6] which consists of multicells. The Level Shifted PWM provides better harmonic cancellation than Phase Shifted PWM. It is of three types as Phase Disposition PWM, Opposition Disposition PWM and Alternate Opposition Disposition PWM

The second stage of SST comprised of DC-DC converter. This stage is generally developed with different converters such as Dual Active Bridge Converter (DAB), LLC Converter as illustrated in Fig. 4 ( $\mathrm{a} \& \mathrm{~b}$ ). The Dual Active Bridge Converter is structured with 1 phase and 3 phase. It consists of two full $\mathrm{H}$ - bridges at primary and secondary of High or Medium Frequency transformer [1] [2]. It consists of lower number of passive devices, so employs soft switching properties. The 3 phase DAB converters achieve better efficiency than 1 phase DAB converter. J. Y. Lee et al. [18] have proposed SST as new Intelligent Semiconductor Transformer (IST) with bidirectional resonant converter. This system have tested with $2 \mathrm{kVA}$ prototype which features as good voltage balancing with simple control for bidirectional power flow but the system performance efficiency improvement is the scope of future work.

The LLC converter is a DC-DC resonant converter consists of series connected capacitor with transformer leakage inductance to prevent the saturation of transformer. It provides better efficiency but the switching frequency becomes uncontrollable at no load condition.

These converters are operated with modulation schemes as shown in Fig. 5. The Phase Shift Modulation has simple operational algorithm and can transfer highest power but causes higher losses al low power levels. The Trapezoidal Modulation minimizes the switching losses but shows higher conduction losses and has complex control and modulation algorithm. As compared to Phase Shift Modulation the Triangular Modulation provides lower switching losses but requires complex switching control and modulation algorithm.

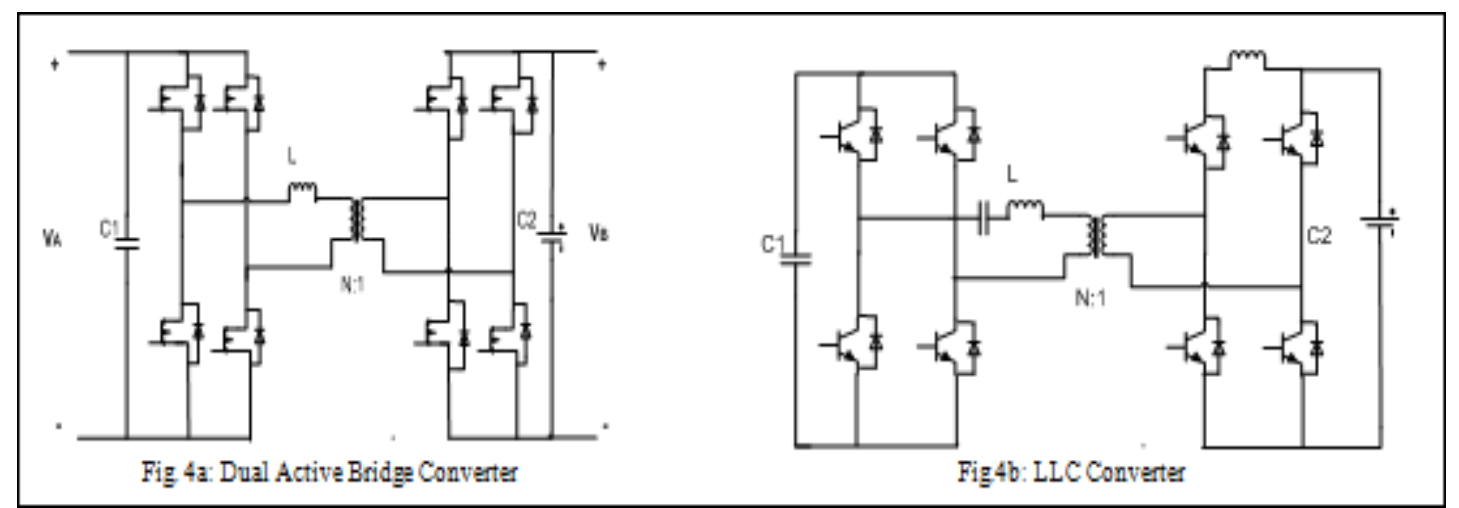

Fig. 4: Second stage: DC/DC Converters

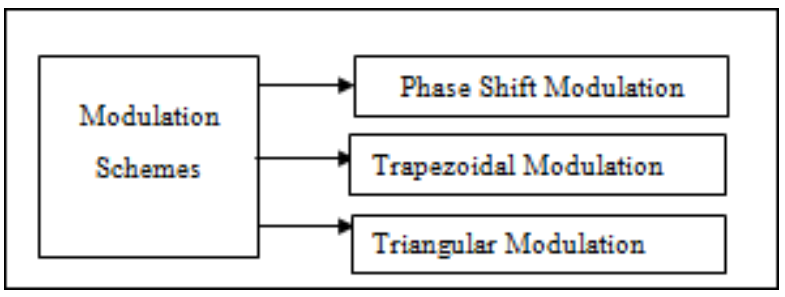

Fig 5: Modulation Techniques for DC/DC Converters 


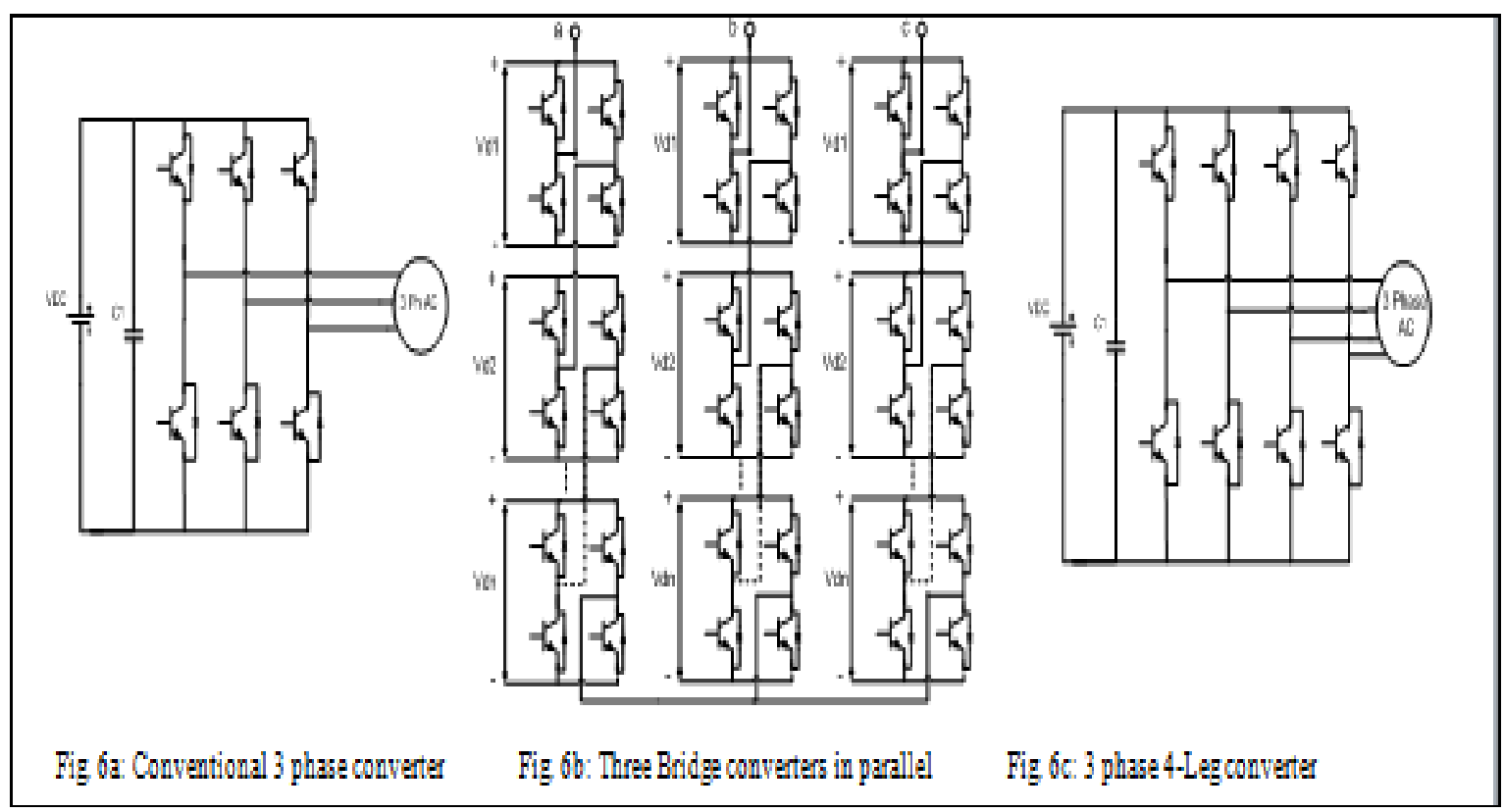

Fig 6: Third stage: DC/AC Converters

The third stage of SST consists of DC- AC converter. It can be employed with different converter topologies such as conventional 3 phase converter, 3 bridge converters in parallel combination, 3 phase 4-leg converter etc. as illustrated in fig (6a-c). The 3 bridge converters connected in parallel may be consisting of half bridge cells or full bridge cells. It requires lower number of switches and lower DC link voltage but causes voltage imbalance issues. The conventional 3 phase converter does not require separate DC source like $\mathrm{CHB}$ converters but causes voltage unbalance across capacitors. The 3 phase 4 leg converters minimize the problems of capacitor voltage unbalancing which is the disadvantage of conventional 3 phase converter by adding another switching leg. This topology requires complex control technique. This topology shows suitability for applications of unbalanced loads.

H. ImanEini et al. have presented SST as Power Electronics Transformer (PET) with cascaded $\mathrm{H}$ bridge converter topology for critical loads. The results have analyzed for conferment of usefulness of PET for power quality improvement. The system provides the scope to research on improvement of efficiency at isolation and output stages. Yashan Liu, et al. [19] have proposed model predictive control for SST designed with two $3 \mathrm{ph}$ to $1 \mathrm{ph}$ matrix converter based SST. The system has analyzed carrying out simulation studies with variable voltage and load power variations. The control strategy employed reduces complexity of other traditional control and modulation strategies with improved performance of SST.

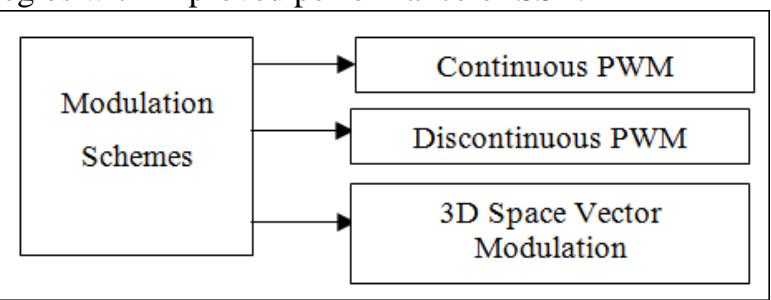

Fig 7: Modulation Techniques for DC/AC Converters

These converter topologies can be designed with different modulation techniques as shown in fig. includes Continuous
PWM, Discontinuous PWM and 3D space vector modulation. The Continuous PWM provides easy and simple algorithm and implementation. The Discontinuous PWM enables low switching losses and low THD. The 3D Space Vector Modulation requires complicated calculations and control algorithm.

\section{CONCLUSION}

In this paper the various converter topologies with its control and modulation techniques have discussed with the structures. Thus the combination of converter topologies and its control and modulation schemes for SST suitable for various applications such as drives control, integration of renewable energy sources to grid, electrification, for fault tolerant applications depends upon the features, advantages and disadvantages of it. The most suited converter topologies for three stages of SST are Cascaded H Bridge converter, Dual Active Bridge Converter with Phase Shifted Modulation and 3 phase 4 leg converter with Continuous Pulse Width Modulation respectively for three stage SST suited to various purpose and applications. The SST offers various features which may leads the maximum research in various transmission and distribution applications.

\section{REFERENCES}

1. B. Zhao, Q. Song, and W. Liu: Power characterization of isolated bidirectional dual-active-bridge dc-dc converter with dual-phase-shift control, IEEE Trans. Power Electron., vol. 27, no. 9, pp. 4172-4176, 2012.

2. C. Mi, H. Bai, C. Wang, and S. Gargies: Operation, design and control of dual H-bridge-based isolated bidirectional DC-DC converter, IET Power Electronics, vol. 1, no. 4 pp. 507-517, 2008

3. Dan Wang, ChengxiongMaoa, JimingLua, Shu Fan, FangzhengPeng: Theory and application of distribution electronic power transformer, Elsevier, Electric Power Systems Research 77, pp. 219-226, 2007. 
4. D.K. Rathod: Solid State Transformer (SST): Review of Recent Developments, Advance in Electronic and Electric Engineering, ISSN 2231-1297, Volume 4, Num. 1, pp. 45-50, 2014.

5. H. Hooshyar and M.E. Baran: Fault Analysis on Distribution Feeders Employing SST, in Proc. IEEE, Power and Energy Society General Meeting, pp.1-5, 2014.

6. Iman-Eini, H.; Farhangi, S.; Schanen, J.-L.; Aime, J.: Design of Power Electronic Transformer based on Cascaded H-bridge Multilevel Converter, IEEE International Symposium on Industrial Electronics, vol., no., pp.877-882, 4-7, 2007.

7. Imran Syed, VinodKhadkikar: Replacing the grid interface transformer in wind energy conversion system with Solid- State Transformer, IEEE Transactions on Power Systems, pp.1-10, 2016.

8. J. L. Brooks: Solid state transformer concept development, in Naval Material Command. Port Hueneme, CA: Civil Eng. Lab., Naval Construction Battalion Center, 1980.

9. J. W. Kolar and G. Ortiz: Solid-State-Transformers: Key Components of Future Traction and Smart Grid Systems, IEEE International Power Electronics Conference - ECCE Asia, 2014.

10. J. W. V. D. Merwe and H. du Mouton, The Solid-State Transformer Concept: A New Era in Power Distribution, in AFRICON 2009, 2009.

11. M.D. Manjrekar, R. Kieferndorf, and G. Venkataramanan: Power Electronic Transformers for Utility Applications, Trans of China electro-technical society, vol. 16, no. 5, pp. 2496-2502.

12. SixifoFalcones, RajapandianAyyanar, Xiaolin Mao: A DC-DC multiport-converter-based solid-state transformer integrating distributed generation and storage, IEEE Transactions On Power Electronics, vol. 28, no. 5, pp.2192-2203, 2013.

13. SubhadeepPaladhi and Ashok S: Solid State Transformer application in wind based DG system, IEEE, pp. 1-5, 2015.

14. W. A. Rodrigues, R. A. S. Santana, A. P. L. Cota, T. R. Oliveira, L. M. F. Morais, P. C. Cortizo: Integration of Solid State Transformer with DC Microgrid System, IEEE, pp. 1-6 2016.

15. Xu She, Alex Q. Huang and Rolando Burgos: Review of Solid-State Transformer Technologies and Their Application in Power Distribution Systems, IEEE Journal of Emerging And Selected Topics In Power Electronics, Vol. 1, No. 3, pp.-186-198, 2013.

16. Liu G, Polis MP, Wang B: Solid-state power transformer circuit. Patent No.: 5119285, 1992.

17. Ronan ER, Sudhoff SD, Glover SF, et al.: Application of power electronics to the distribution transformer. IEEE Applied Power Electronics Conference and Exposition (APEC). IEEE, 861-867, 2000.

18. Lee JY, Yoon YD, Han BM: New intelligent semiconductor transformer with bidirectional power-flow capability. IEEE T Power Deliver 29: 299-301, 2014.

19. Liu Y, Liu Y, Abu-Rub H, et al.: Model predictive control of matrix converter based solid state transformer, IEEE International Conference on Industrial Technology (ICIT). IEEE, 1248-1253, 2016.

20. ArindamMaitra, Ashok Sundaram, Mahesh Gandhi, Simon Bird, Shoubhik Doss: Intelligent Universal Transformer Design and Applications, CIRED2009, 20th International Conference on Electricity Distribution Prague, June 2009. 